\title{
Fx Calories Calculator \& Fitness ADVISOR
}

\author{
N.Shahul Ashfar ${ }^{1}$ and J.Abalin Lurther ${ }^{2}$ and L.Antro James ${ }^{3}$ \\ ${ }^{1}$ Department of Computer Applications, Francis Xavier Engineering College \\ ${ }^{2} \mathrm{AP}$, Department of Computer Applications, Francis Xavier Engineering \\ College \\ ${ }^{3}$ Department of Computer Applications, Francis Xavier Engineering College
}

\begin{abstract}
Calorie counter to record and estimate number of calories we need to consume daily. "FITNESS START WITH WHAT WE EAT". This project can also provide guidelines for gaining or losing weight. That have heard it way to get started with the very boring term dieting. A number of mobile fitness devices as well as smart watches have emerged on the technology landscape. Body Mass Index is a simple calculation using a person's height and weight. A BMI of 25.0 or more is overweight, while the healthy range is 18.5 to 24.9. Serious fat-burning activity uses the large muscle groups of the body - the thighs and bottom, chest and back. The greater the overall recruitment of muscle, the higher the calorie expenditure. So in your workouts, That are much better off using, say, the rower than isolating your arms for maximum calorie burn.
\end{abstract}

\section{KEYWORDS}

component, formatting, style, styling, insert (keywords)

\section{INTRODUCTION}

This Calorie Calculator is based on several equations, and the results of the calculator are based on a estimated average. The Harris-Benedict Equation was one of the earliest equations used to calculate basal metabolic rate (BMR), which is the amount of energy expended per day at rest. It was revised in 1984 to be more accurate and was used up until 1990, when the Mifflin-St Equation was introduced. The Mifflin-St Equation also calculates BMR, and has been shown to be more accurate than then revised Harris-Benedict Equation. The Katch-McArdle Formula is slightly different in that it calculates resting daily energy expenditure (RDEE). 


\section{ArChitectural Diagram}

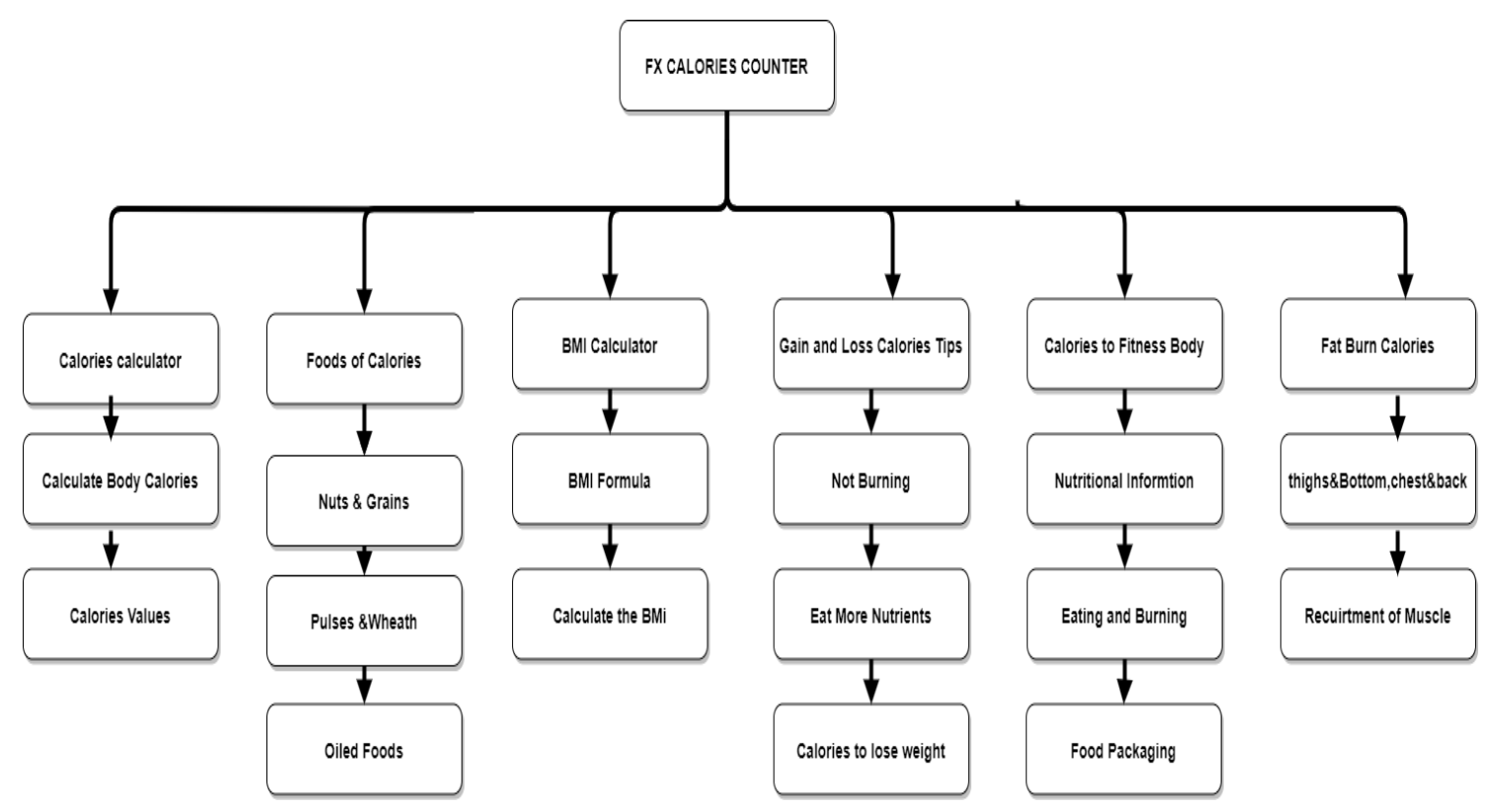

Fig-1 Architecture Diagram

\section{EXPERIMENTS AND RESULTS}

\section{A. Module}

The project "FX CALORIES CALCULATOR \& FITNESS ADVISOR" consists 5 modules for optimizing

\section{User and Admin Accounts}

Admin can monitor the user and the user details. Admin is authorised to add, updated and deleted slots. Admin can view the page. Unlike users, admins have access to the Account Dashboard and billing information. Admin is the role with the highest level of access to your website. Admins can add content on all pages and access all items in the Admin Toolbar. Instead, authors are assigned a specific page (or pages) of the website on which they can add content. Any changes an author makes are automatically saved, then submitted for review in the notification.

\section{Calories Calculator}

This module can be calculate the total body calories. Body calories may various to consume situational foods. Unwanted calories did not add to take health food fitness body. The "quality" of calories consumed is also important. There are different classifications of foods in terms of calories. This includes high-calorie foods, low-calorie foods, and empty calories. Consistent with their naming, high-calorie foods are foods that are calorically dense, meaning that there are a high number of calories relative to serving size. 


\section{Foods Of Calories}

Nuts and grains increase good calories. Pulses and wheat increase good calories. Oil calories. A calorie is a unit of measurement. A calorie is a unit of energy. Proteins: Red meats, pork, chicken with skin on (roast or broil don't deep fry for your health), salmon or other oily fish, beans, whole milk, eggs, cheese, full-fat yogurt. Carbohydrates: potatoes, brown rice, whole grain pasta, whole grains, whole grain Breads

\section{BMI Calculator}

This module can weight category - underweight, healthy weight, overweight, and obesity. $\mathrm{BMI}=\mathrm{m} / \mathrm{h} 2$. BMI is an inexpensive and easy screening method. The formula is BMI of 25.0 or more is overweight. health is at risk. BMI is 17.5. This means that you are underweight. Being underweight makes you more prone to diseases because it signifies that your body's immunity is weak. Children's BMI values are compared with other children of the same age and sex and a percentile is calculated.

\section{Fat Burn Exercises}

Serious fat-burning activity uses the large muscle groups of the body - the thighs and bottom,chest and back. The greater the overall recruitment of muscle, the higher the calorie expenditure. Caffeine is a substance commonly found in coffee, green tea and cocoa beans.Green Tea Extract. Green tea extract is simply a concentrated form of green tea. Protein Powder. Protein is incredibly important for burning fat.Soluble Fiber. There are two different types of fiber - soluble and insoluble. .Yohimbine.

\section{B. Output Screen}

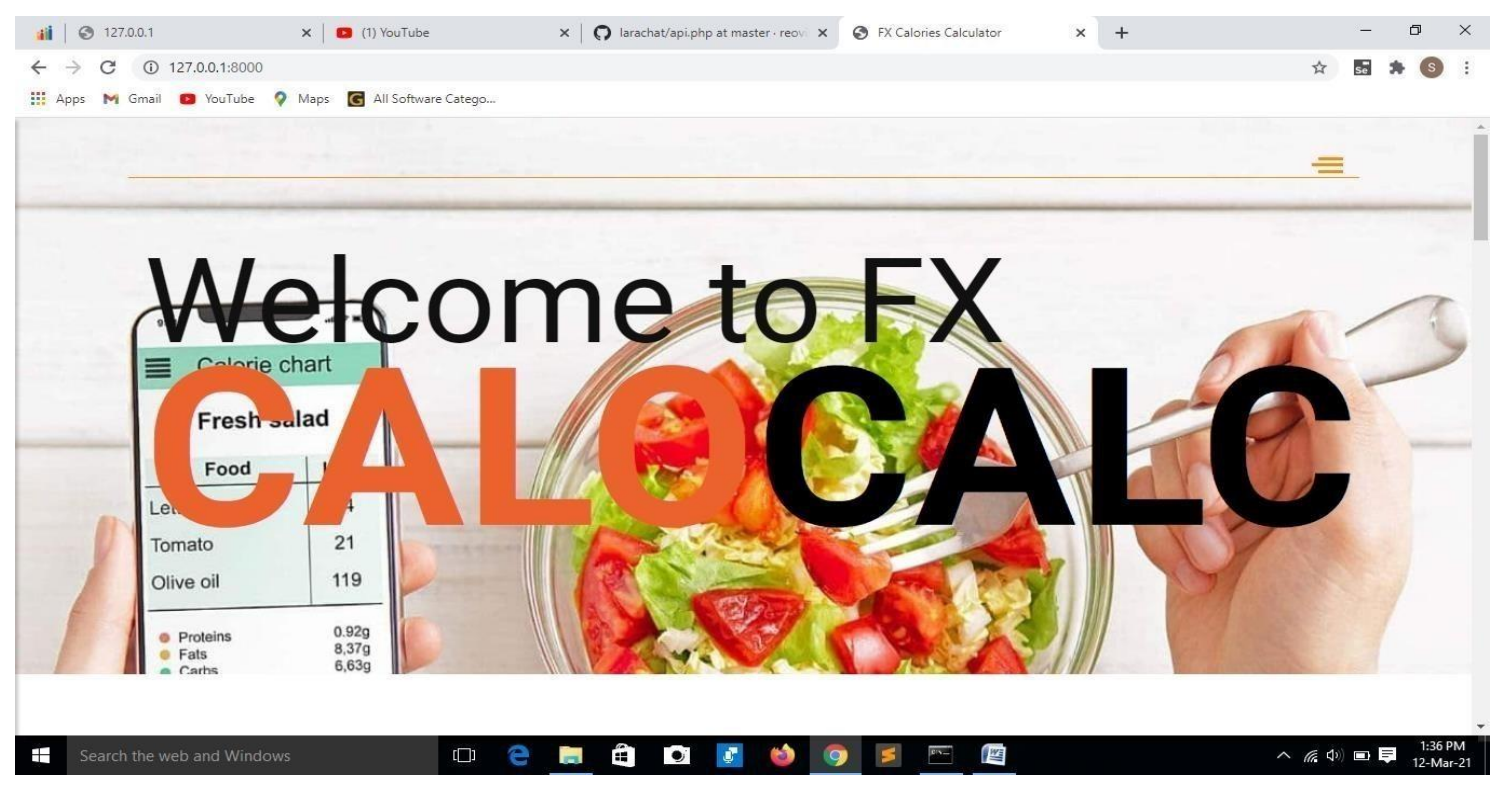

Fig-1 Home Page 


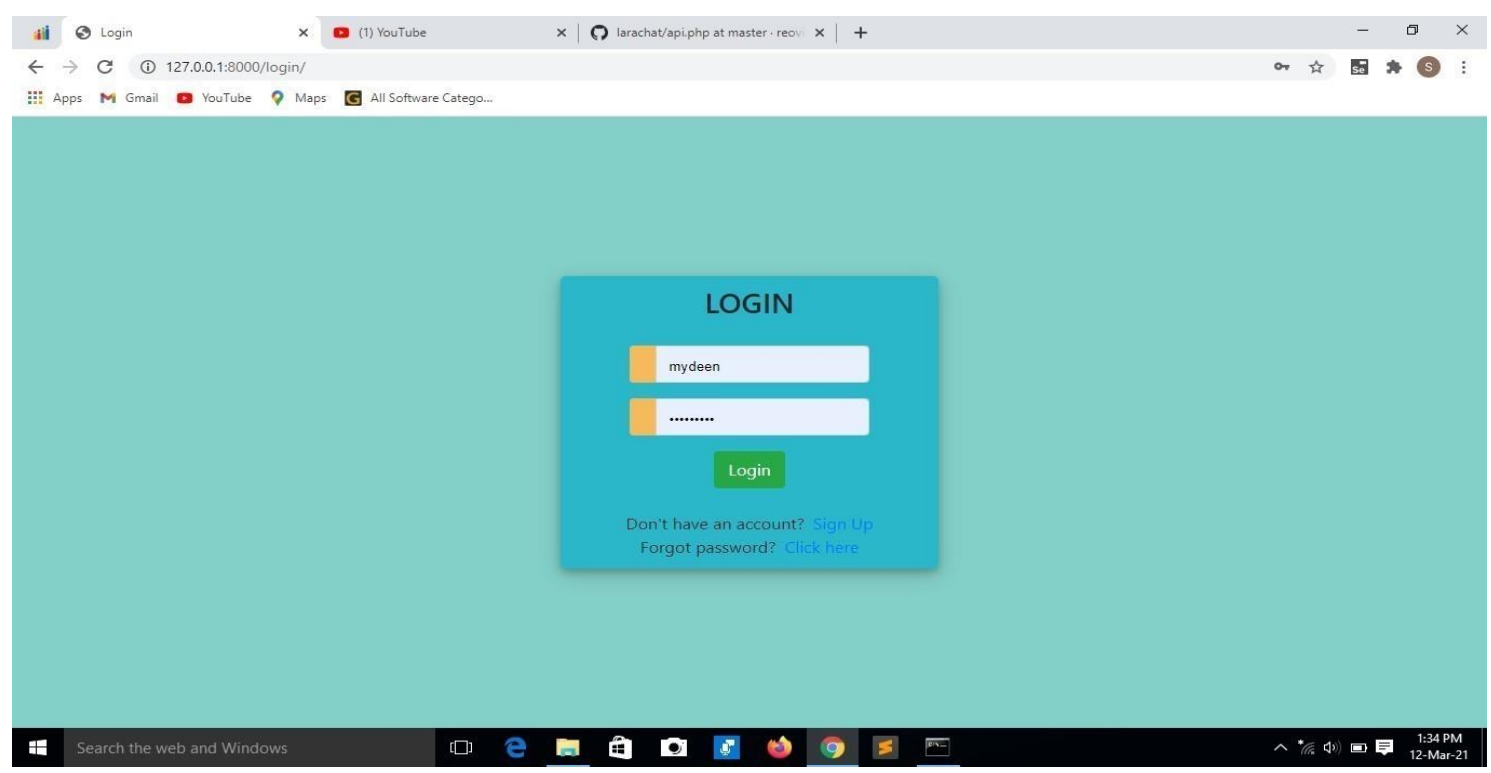

Fig-2 Login Page

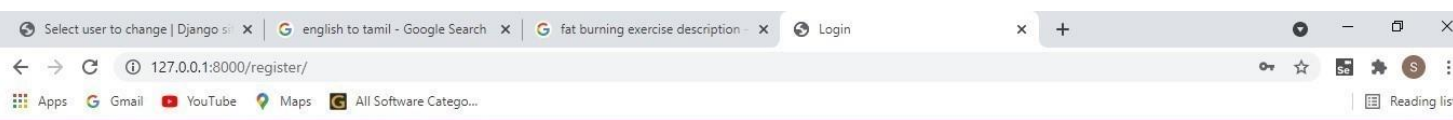

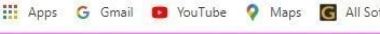

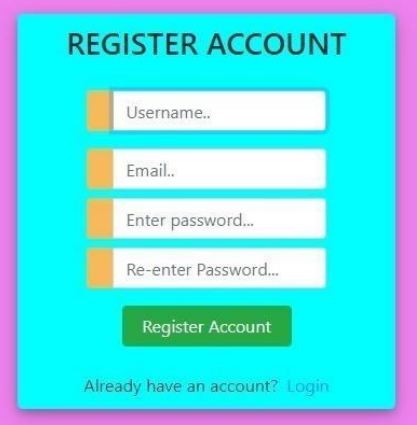

Fig-3 Register Page 


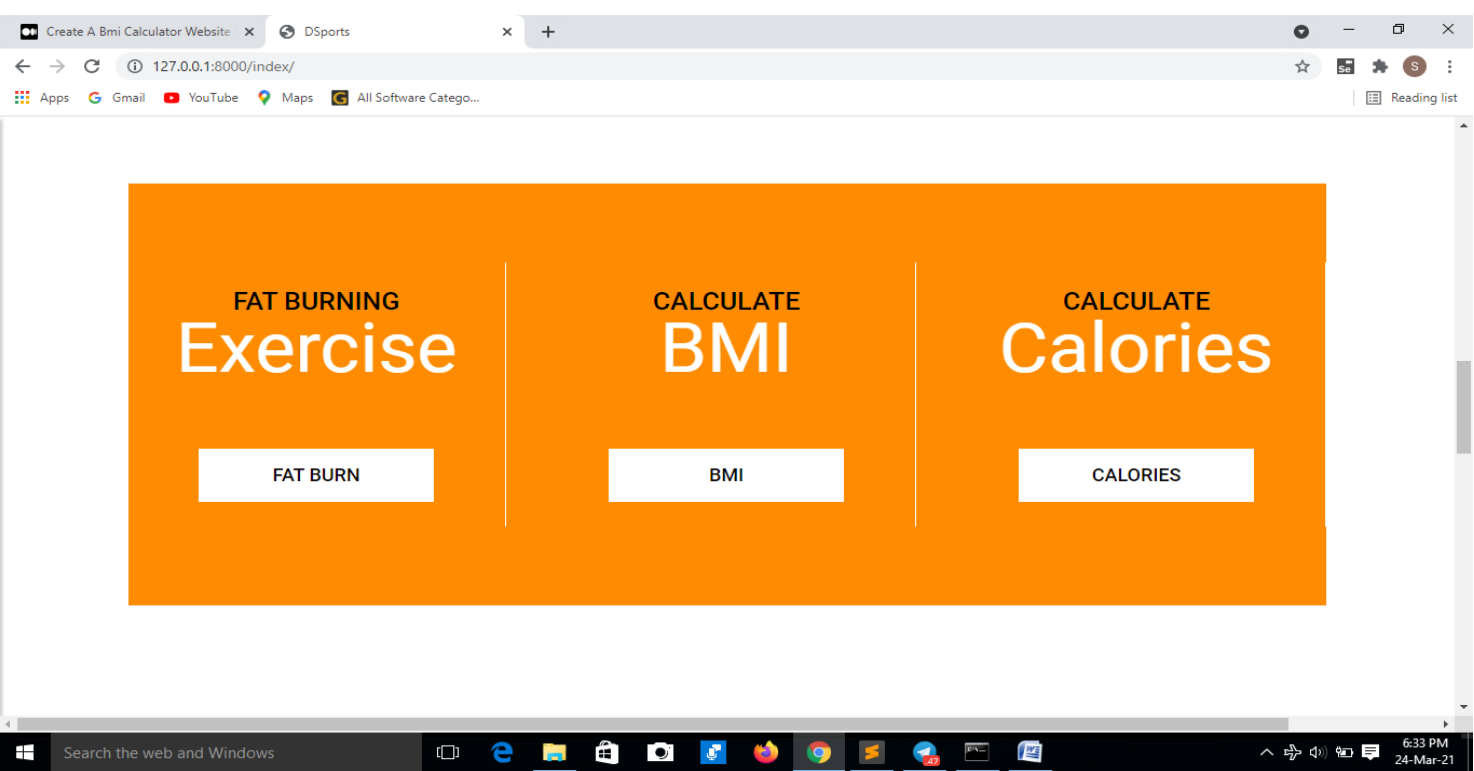

Fig-4 Modules Page

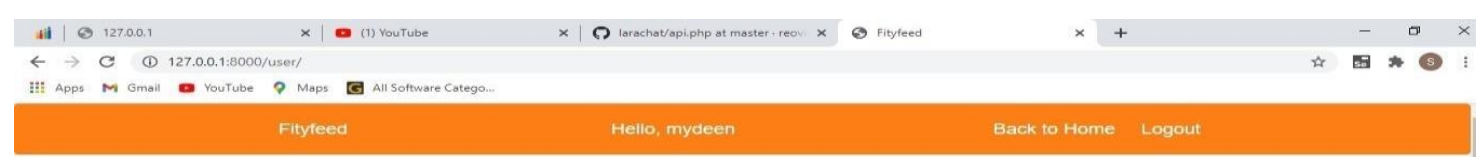

Total number of items consumed today: 3

Tracker

Calorie Limit: 2000

totalCalories consumed: 304.00

Left: 1696.00

\begin{tabular}{|c|c|}
\hline $\begin{array}{l}\text { Tooditem } \\
\text { banana } \\
\text { apple } \\
\text { sprouts }\end{array}$ & $\begin{array}{l}\text { Calorie } \\
96.00 \\
56.00 \\
152.00\end{array}$ \\
\hline+ & \\
\hline
\end{tabular}

Fig-5 Calories Calculating 

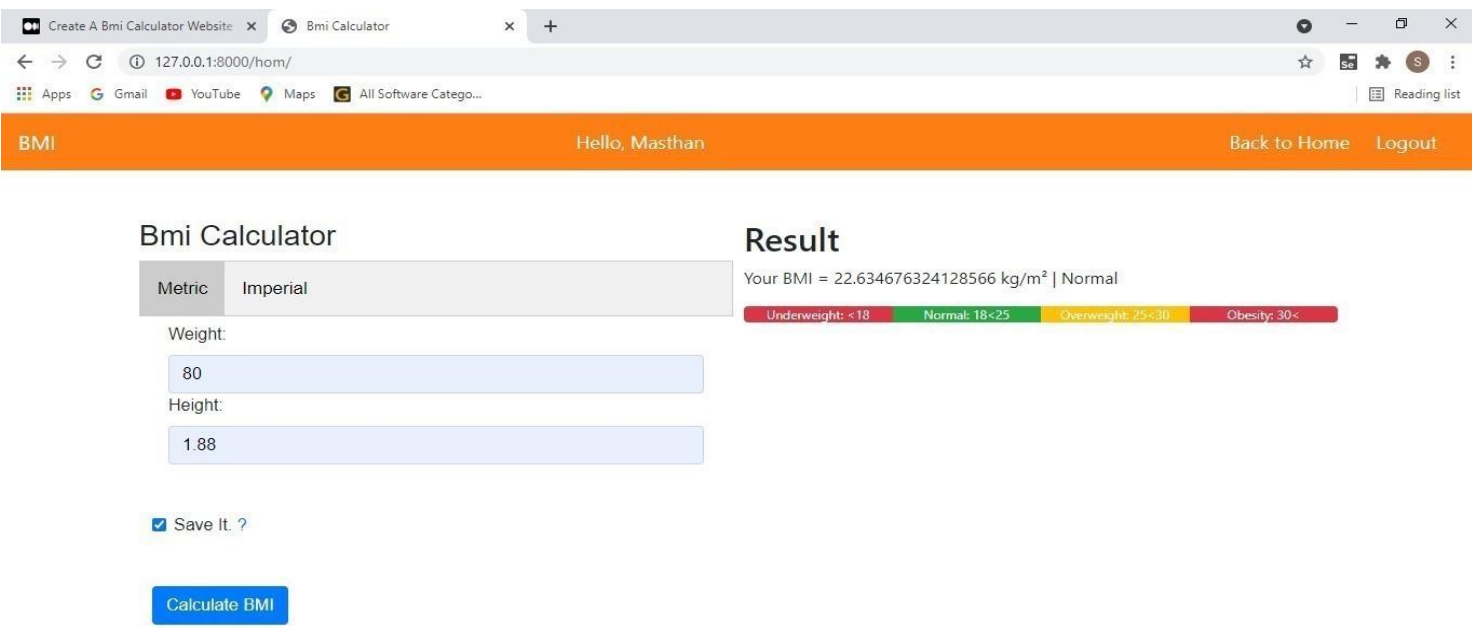

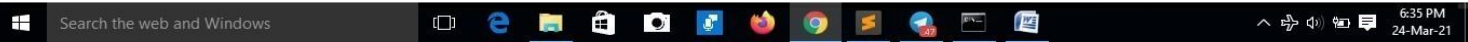

Fig-6 BMI Calculating

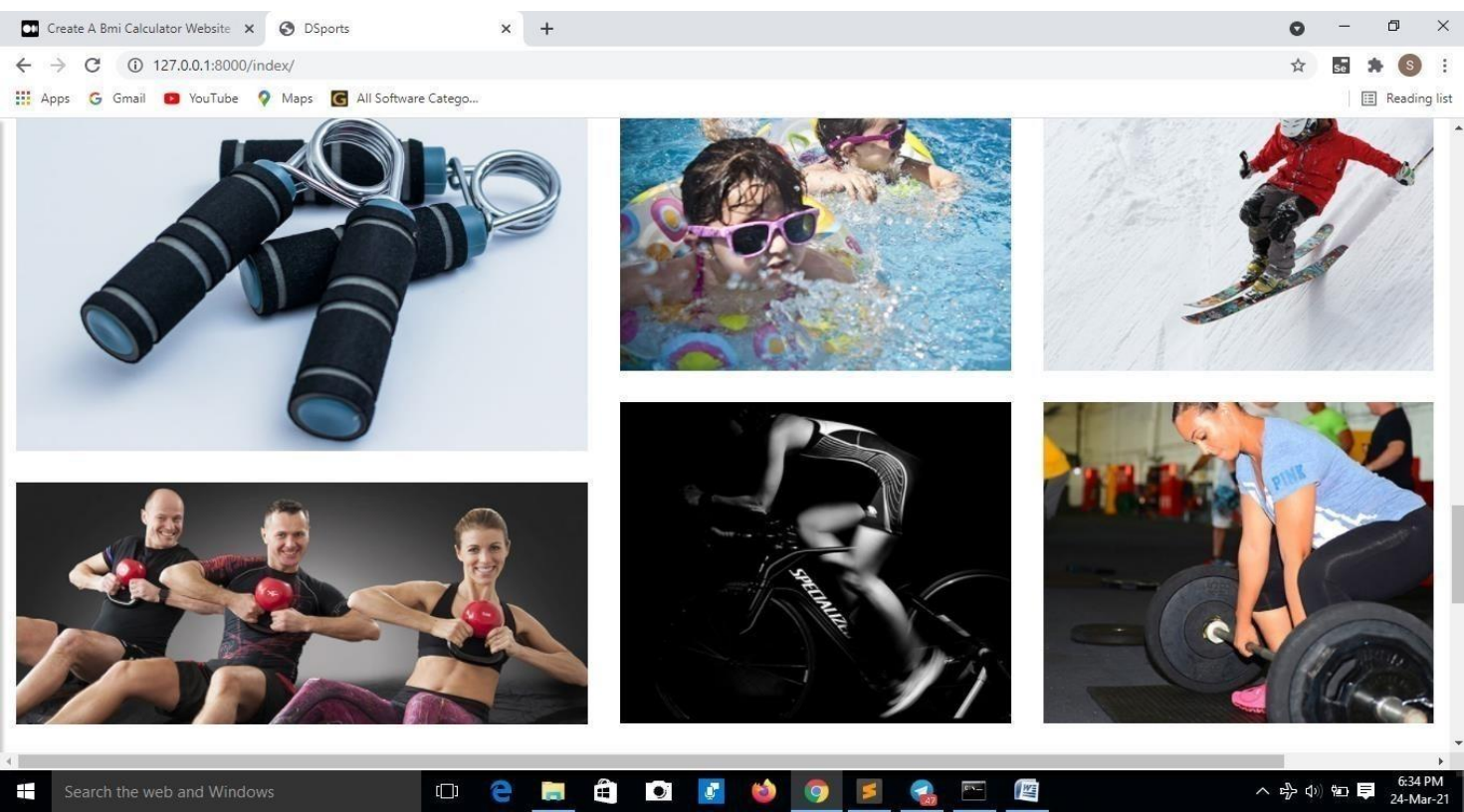

Fig-7 Exercise Page

\section{Performance Analysis}

The existing and proposed system are analysed. The identified existing is system will also help in providing real time information provides some avenues for future research on IoT-based health care based on a set of open issues and challenges.Nearly $70 \%$ performance has been increased. 


\section{CONCLUSiON}

All foods, including "healthful foods," should be consumed in moderation, and distinctions can often be misleading since even natural foods like fruits can have large amounts of sugar,and foods labeled as "health foods" such as low-calorie foods, reduced-fat foods, etc. Can potentially replace one unhealthy component with another. it greatly ease users who would like to quickly snap a picture and record their calorie intake. A prototype is developed to test and face the challenges of recognizing Malaysian traditional food.

\section{FUTURE ENHANCEMENT}

It is important to remember that proper diet and exercise is largely accepted as the best way to lose weight. It contains to business related of sales to some nutritional clinics.It is inadvisable to lower calorie intake by more than 1,000 calories per day, as losing more than 2 pounds per week can be unhealthy, and can result in the opposite effect in the near future by reducing metabolism.

\section{REFERENCES}

[1] Ng M, Fleming T, Robinson M, et al. Global, regional, and national prevalence of overweight and obesity in children and adults during 1980-2013: a systematic analysis for the Global Burden of Disease Study 2013. Lancet 2014; 384(9945): 766-781.

[2] Giugliano D, Ceriello A, Esposito K. The effects of diet on inflammation: emphasis on the metabolic syndrome. J Am Coll Cardiol 2006;48:677-85.

[3] Bailey, S., Gerada, C., Lester, H. \&amp; Shiers, D. (2012). The cardiovascular health of young people with severe mental illness: addressing an epidemic within an epidemic. The Psychiatrist, 36, 375378.

[4] C. P. Lambert, L. L. Frank and W. J. Evans, "Macronutrient considerations for the sport of bodybuilding," Sports Med. 2004;34(5):317-27

[5] Longo VD, Mattson MP. Fasting: molecular mechanisms and clinical applications. Cell Metab 2014;19:181-92.

[6] Stephanie B. Baker; Wei Xiang; Ian Atkinson: "Internet of Things for Smart Healthcare: Technologies, Challenges and Opportunities", IEEE Access ( Volume: 5), DOI: 10.1109/ACCESS.2017.2775180 


\section{AUTHORS}

N.SHAHUL ASHFARN doing final year MCA in Francis Xavier Engineering College.

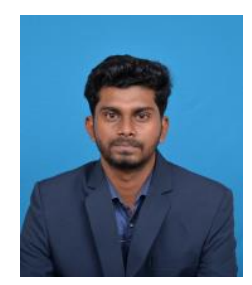

Mrs. J. ABALIN LUTHER is working as Assistant Professor in the Department of Computer Applications, Francis Xavier Engineering College. She is having teaching experience of $5+$ years. Her area of interest is Wireless Sensor networks.

L.ANTRO JAMES Doing first year MCA in Francis Xavier Engineering College.

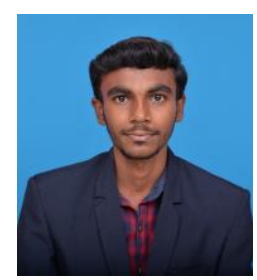

